\title{
A Novel Rectangular Dielectric Resonator Antenna for Dual-band Application
}

\author{
Manyuan Dai, a , Hu Yang ${ }^{1, b}$, Lei Gu ${ }^{2, c}$, Fei Zhao ${ }^{2}$ and Wenlu Yin ${ }^{2}$ \\ ${ }^{1}$ Electronic Science and Engineering Department, National University of Defense Technology, \\ 410073 Changsha, Hunan province, China. \\ ${ }^{2}$ Southwest Electronics and Telecommunication Technology Research Institute, 610041 Chengdu, \\ Sichuan province, China. \\ anudt_dai@163.com, byanghu90@163.com, cgulei100121@sina.com
}

Keywords: dual-band antenna; rectangular DRA; stripline-feeding; satellite communication systems

\begin{abstract}
To meet the dual-band requirements of satellite communication systems, a novel rectangular dielectric resonator antenna (DRA) is presented. In general, most of the rectangular DRA is fed by slot coupled with microstrip line. But when the antenna is placed on a metallic ground according to the actual conditions, both the operating bands and patterns of the DRA are changed. To solve this problem, a novel feeding structure using slot coupled with stripline is studied. Then a rectangular DRA with slot-coupled stripline-feeding is designed, which operates at Ku-band with downlink frequency band of 12.25-12.75 GHz and uplink frequency band of 14-14.5 GHz. Also, the simulated results show that the radiation characteristics of the novel DRA are changed small with a metallic ground under the antenna, which demonstrates that it is more profitable for engineering.
\end{abstract}

\section{Introduction}

With the development of satellite communication system, a higher performance of antenna is required now. The system requires that antenna has not only miniaturizaton, light weight, good concealment, mobility and transceiver integration, also dual-band and high gain characteristics. Dielectric resonator antennas were first investigated by Long et al. in 1983 [1]. DRAs have several advantages, such as wideband performance, compact size, low-profile ease of excitation and fabrication, high power capabilities, conformability to curved surfaces and high radiation efficiency $[2,3]$. Therefore, various modes can be excited because of different shapes and feeding, resulting in favorable dual-band, dual-polarization and other characteristics. By these reasons, DRA has attracted tremendous attention in recent years for the satellite communication system.

The basic structure of a dielectric resonator antenna is composed of a dielectric element with a specific shape, such as hemispherical, cylindrical, rectangular and triangular, excited by a single feeding, such as microstrip line, coplanar waveguide, aperture and coaxial cable [4]. For the dual-band applications, the common way is to excite two modes of the DRA and each mode operates in one band. In this paper, a normal DRA is designed and excited $\mathrm{TE}_{1 \delta 3}$ mode to operate from 12.25 to $12.75 \mathrm{GHz}$ and $\mathrm{TE}_{1 \delta 5}$ mode to operate from 14 to $14.5 \mathrm{GHz}$. Then a novel dual-band DRA is designed in the same frequency range. Also the impact of the ground plane under both antennas is studied.

\section{The Design of Rectangular DRA with Microstrip line Feeding.}

In designing the rectangular DRA, the dielectric waveguide model (DWM) has been extensively used to determine the resonance frequency of the DRA. A rectangular DRA has three independent dimensions. The modes of a DRA can, therefore, be TE to any of three dimensions [5]. To achieve dual-band of rectangular DRA, a higher mode is often useful.

The geometry of the normal DRA is shown in Fig. 1. The substrate is Rogers 4003C, with the permittivity of $\varepsilon_{r}=3.38$ and height of $s u b_{-} h=0.5 \mathrm{~mm}$. The microstrip line feeding structure is 
matched to $50 \Omega$, with width of feeding $\_w=1.2 \mathrm{~mm}$, length of feeding $\_l=11 \mathrm{~mm}$, and length of ground with ground_l $l=15.2 \mathrm{~mm}$. The rectangular DR is made of a ceramic material with permittivity of 9.8, length $D R A_{-} l=4.66 \mathrm{~mm}$, width $D R A_{-} w=6.3 \mathrm{~mm}$, height DRA_ $h=11.54$ $\mathrm{mm}$. Besides, a slot is etched in the center of upper ground, with length slot_l$=5.13 \mathrm{~mm}$, width slot_w $=0.9 \mathrm{~mm}$.

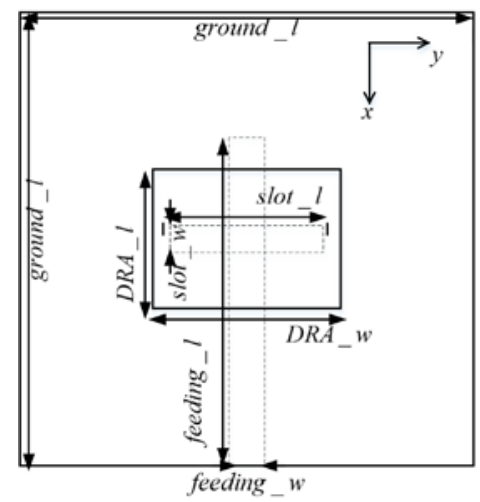

Fig. 1 Geometry of the normal DRA
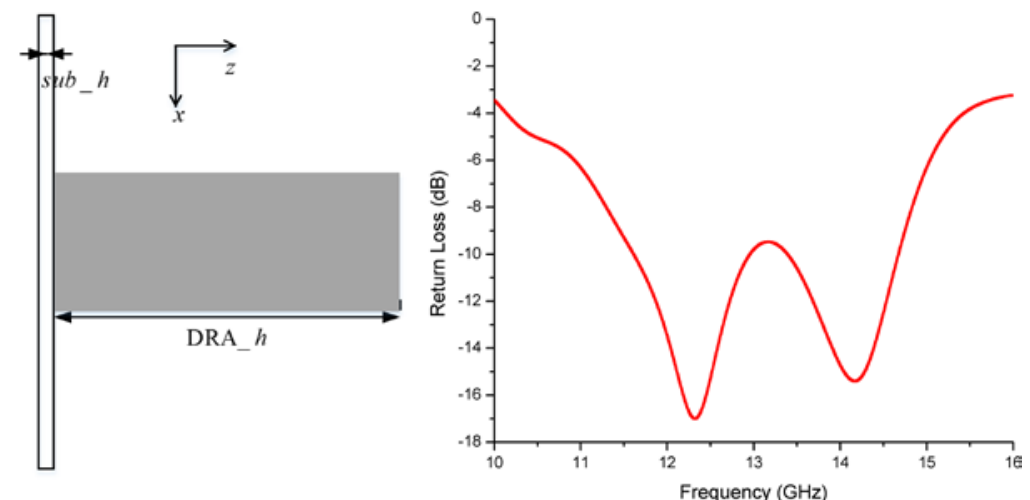

Fig. 2 Simulated return loss of the antenna

The simulated return loss of the normal DRA with slot-coupled microstrip line feeding is shown in Fig. 2. And the return loss is less than $-10 \mathrm{~dB}$ from 11.62 to $12.95 \mathrm{GHz}$ and 13.39 to $14.67 \mathrm{GHz}$, respectively. The simulated radiation patterns of the antenna at $12.5 \mathrm{GHz}$ and $14.25 \mathrm{GHz}$ are shown in Fig. 3 and Fig. 4. As can be seen, the direction of the maximum radiation is along z-axis. The simulated value of the realized gain along z-axis is $8.86 \mathrm{~dB}$ at $12.5 \mathrm{GHz}$ and $8.24 \mathrm{~dB}$ at $14.25 \mathrm{GHz}$. And the realized gain of the back-lobe is $-8.57 \mathrm{~dB}$ at $12.5 \mathrm{GHz}$ and $-4.72 \mathrm{~dB}$ at $14.25 \mathrm{GHz}$. Furthermore, the radiation patterns of the antenna are symmetrical in H-plane in operating bands.

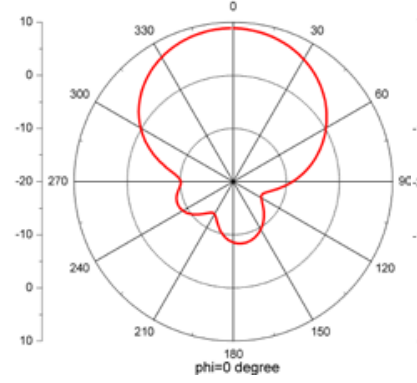

(a) E-plane

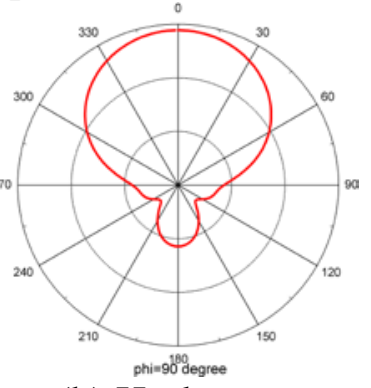

(b) H-plane

Fig. 3 Radiation patterns at $12.5 \mathrm{GHz}$
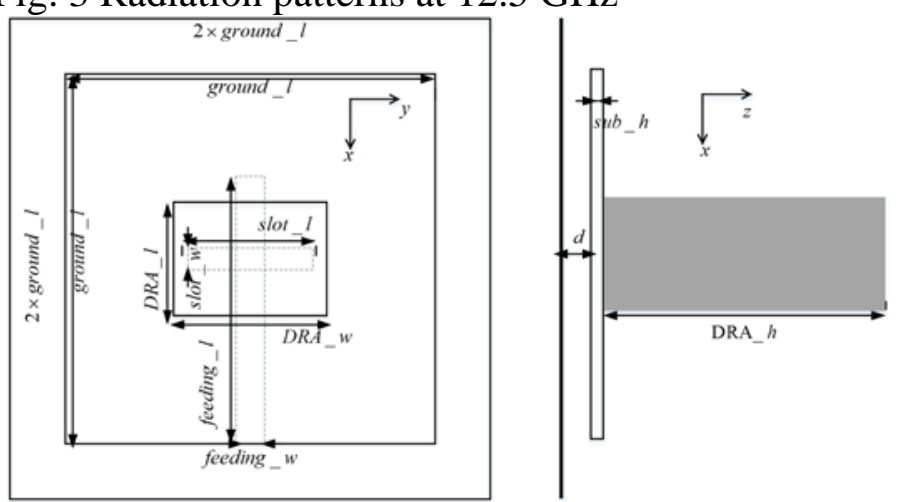

Fig. 5 Geometry of the DRA with metallic ground under the DRA

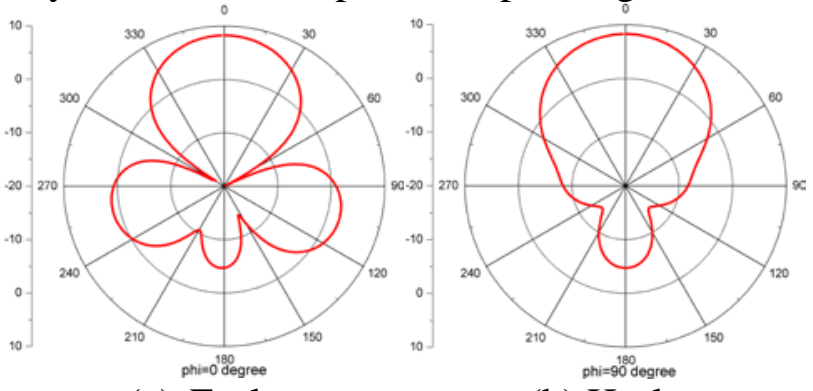

(b) H-plane

Fig. 4 Radiation patterns at $14.25 \mathrm{GHz}$

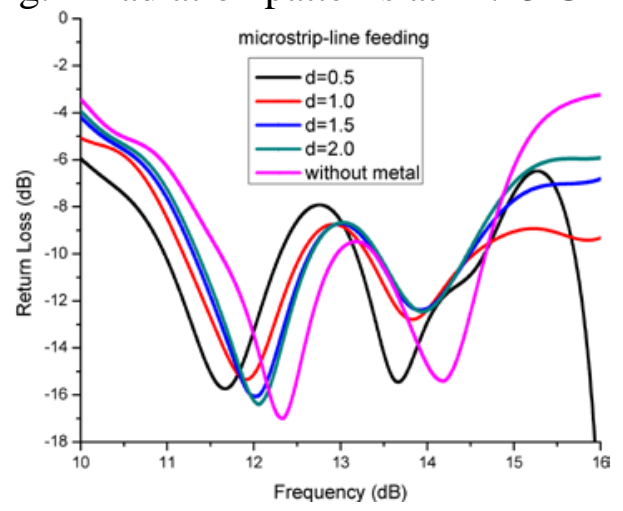

Fig. 6 Return loss of the DRA with d-parameters change

To study the impact of the actual conditions, a square metallic ground is placed under the DRA as shown in Fig. 5. The distance between the DRA and the ground is set as $\mathrm{d}(\mathrm{mm})$. With the change of the parameter-d, both the return loss and the patterns of the antenna are observed in Fig. 6, 7 and 8.

The simulated return loss is changed obviously in Fig. 6. The closer distance between the ground and the antenna, the lower center frequency of both bands can be got. When parameter- $\mathrm{d}$ is $0.5 \mathrm{~mm}$, the low band and the high band decreases $7.6 \%$ and 5.8\% respectively. Also, the return loss are higher. 
For example, the return loss increases $19.2 \%$ at the center frequency of the high band, when parameter-d is $2.0 \mathrm{~mm}$. In Fig. 7 and 8, the simulated far field patterns at $12.5 \mathrm{GHz}$ and $14.25 \mathrm{GHz}$ are shown. In addition, the direction of the max radiation of the antenna is not along z-axis any more. At the same time, the realized gain along z-axis is decreased about $3 \mathrm{~dB}$ at $14.25 \mathrm{GHz}$.

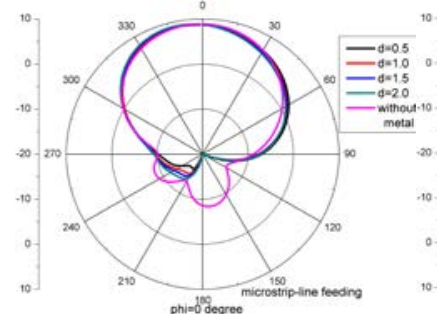

(a) E-plane

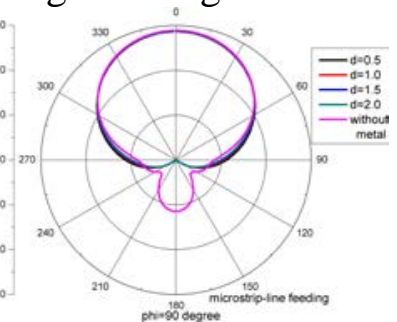

(b) H-plane

Fig. 7 Radiation patterns at $12.5 \mathrm{GHz}$

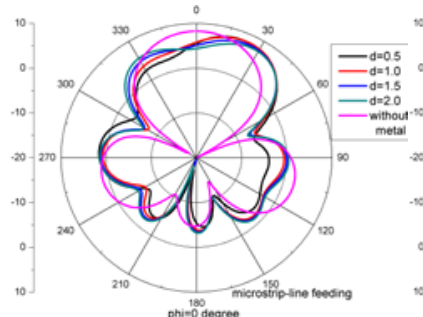

(a) E-plane

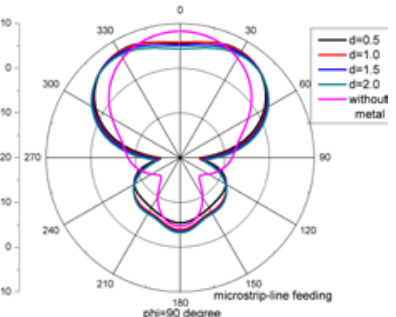

(b) H-plane

Fig. 8 Radiation patterns at $14.25 \mathrm{GHz}$

The Design of Rectangular DRA with Stripline feeding.

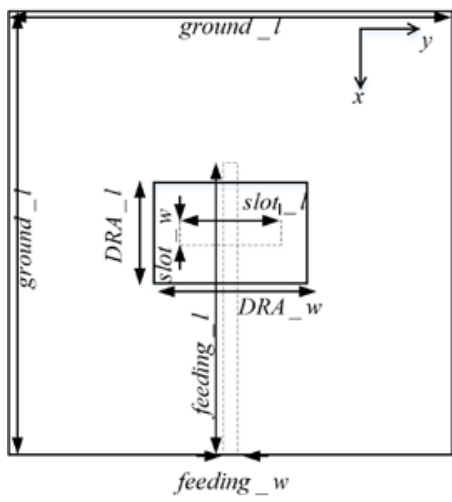

Fig. 9 Geometry of the novel DRA

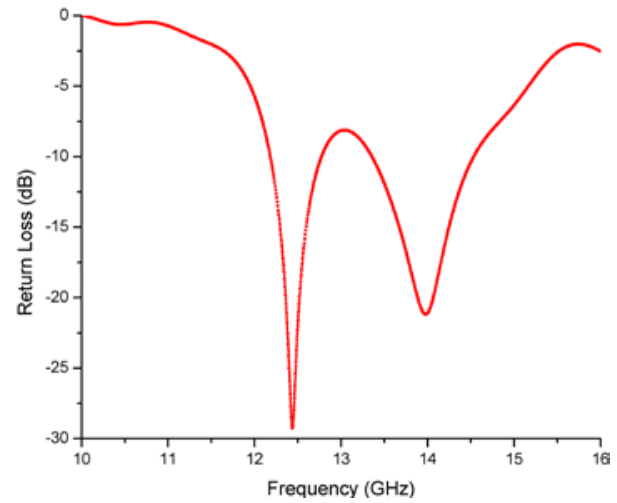

Fig. 10 Return loss of the DRA

The novel rectangular DRA is fed by stripline in Fig. 9. The materials used here are same with the normal DRA. The size parameters of the novel DRA are shown in Table 1.

Table 1 . The size parameters (mm) of slot-coupled stripline-fed DRA

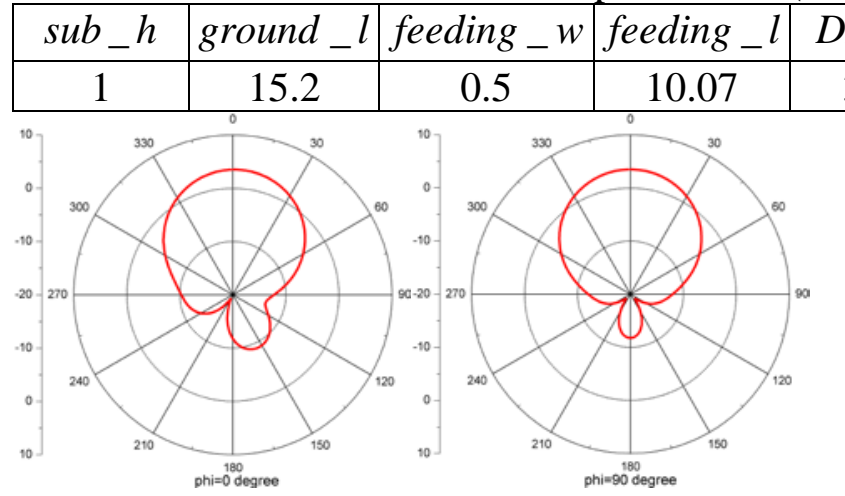

(a) E-plane (b) H-plane

Fig. 11 Radiation patterns at $12.5 \mathrm{GHz}$

\begin{tabular}{c|c|c|}
\hline$D R A_{-} l$ & $D R A_{-} w$ & DRA_h $^{2}$ \\
\hline 3.46 & 5.24 & 9.61 \\
\hline
\end{tabular}

(a) E-plane

\begin{tabular}{|c|c|}
\hline slot_l & slot_w \\
\hline 3.47 & 0.85 \\
\hline
\end{tabular}

As can be seen in Fig. 10, the return loss is less than $-10 \mathrm{~dB}$ from 12.20 to $12.80 \mathrm{GHz}$ and 13.44 to 14.7 GHz, respectively. The simulated radiation patterns of the antenna at $12.5 \mathrm{GHz}$ and $14.25 \mathrm{GHz}$ are shown in Fig. 11 and Fig. 12. The direction of the max radiation is along $z$-axis. The simulated max value of the realized gain is $4.07 \mathrm{~dB}$ at $12.5 \mathrm{GHz}$ and $7.43 \mathrm{~dB}$ at $14.25 \mathrm{GHz}$. And the value of the realized gain of the back-lobe is $-11.72 \mathrm{~dB}$ at $12.5 \mathrm{GHz}$ and $-13.77 \mathrm{~dB}$ at $14.25 \mathrm{GHz}$, which is much smaller than the normal DRA. The realized gain is much lower than microstrip line feeding at 12.5 $\mathrm{GHz}$, due to the slot resonance, instead of dielectric resonator. Then the novel DRA with metallic ground in the back is studied. 


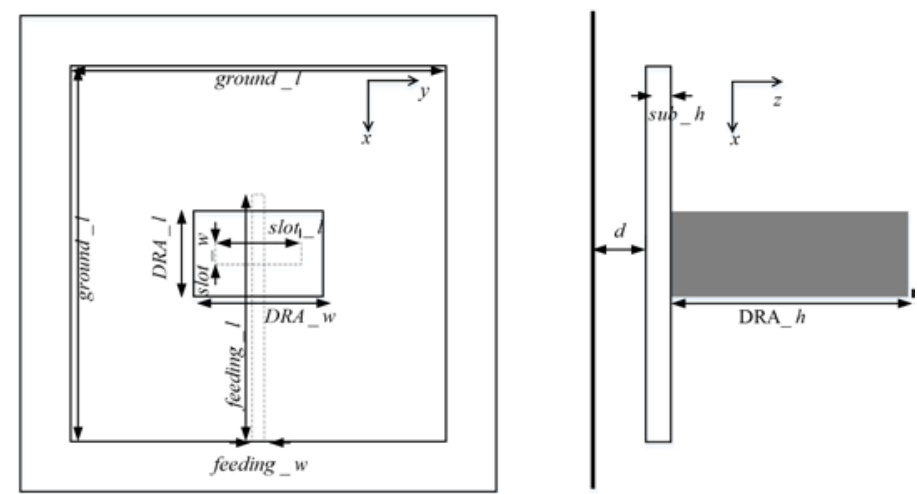

Fig. 13 Geometry of DRA with metallic ground under the DRA

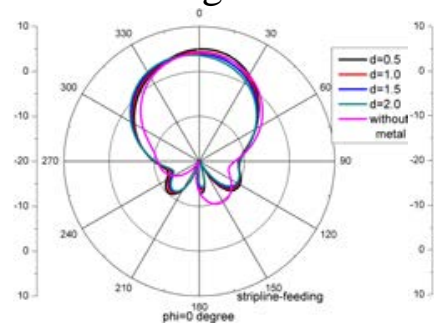

(a) E-plane

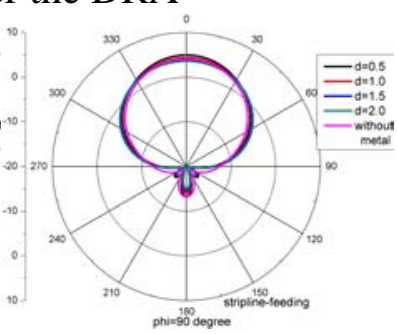

(b) H-plane

Fig. 15 Radiation patterns at $12.5 \mathrm{GHz}$

The simulated return loss is almost no change in Fig. 14. At the same time, the realized gain of radiation patterns of the novel DRA with stripline feeding is changed less than $1 \mathrm{~dB}$ in Fig. 15 and Fig. 16. Therefore, the novel DRA is affected less with ground in the back, compared with the normal DRA.

\section{Summary}

The dual-band rectangular DRA with microstrip line feeding has attracted lots of attention. The DRA with stripline feeding has not been investigated yet. Compared with the normal slot-coupled microstrip line feeding, the novel DRA with slot-coupled stripline feeding has lower back-lobe radiation. In addition, the performance of the novel DRA is almost not affected by metal materials in the back, which can be more adapted to the actual work conditions.

\section{References}

[1] S. A. Long, M. W. McAllister, and L. C. shen. "The resonant cylindrical dielectric cavity antenna.” IEEE Transactions on Antennas and Propagation, vol. 31, pp. 406-412.

[2] A. Petosa. Dielectric Resonator Antenna Handbook. Artech House, 2007

[3] Lin Yi, He Yan, Manyuan Dai. He Wang and Hu Yang. "Design of a $\mathrm{Ka} / \mathrm{Ku}$ Dual-Band Dual-Polarized Array.” Antennas and Propagation (APCAP), $20143^{\text {rd }}$ Asia-Pacific Conference on. IEEE, 2014

[4] He Yan, Lin Yi and Zhenghe Feng. "A novel dual-polarized dielectric resonator antenna designed for WLAN applications.” Antennas and Propagation (APCAP), $20143^{\text {rd }}$ Asia-Pacific Conference on. IEEE, 2014

[5] R. K. Mongia and A. Ittipiboon. "Theoretical and experimental investigations on rectangular dielectric resonator antennas.” IEEE Transactions on Antennas and Propagation, vol. 45, no. 9, pp. 1348-1356, Sep. 1997. 